\title{
Flow-Injection Determination of Complexing Capacity Corresponding to EDTA and Diphosphate Type Ligands for Some Metal Ions
}

\author{
Norio Teshima, Hajime Yasoda, Makoto KuriHara and Takuji Kawashima ${ }^{\dagger}$ \\ Laboratory of Analytical Chemistry, Department of Chemistry, University of Tsukuba, \\ Tsukuba 305-8571, Japan
}

Keywords Complexing capacity, EDTA, diphosphate, flow-injection, photometry

Studies of metal speciation are still of great importance in various fields. The reason for this situation is that chemical-speciation data can be used to predict the behavior of trace metals in natural water and to investigate biogeochemical processes. ${ }^{1-3}$ The measurement of the metal complexing capacity (CC), which is introduced for environmental assessment ${ }^{4-6}$, is one form of chemical speciation. Reviews on the analytical methods used to measure $\mathrm{CC}$ have already appeared..$^{7-9}$ According to these reviews, previous studies of metal $\mathrm{CC}$ in natural water have focused on the measurement of copper $\mathrm{CC}(\mathrm{CuCC})$.

During the last decade, numerous methods have also been proposed for measuring the $\mathrm{CuCC}$ of naturally occurring ligands using voltammetry ${ }^{10-14}$, a back-extraction technique ${ }^{15-17}$, ion-exchange ${ }^{18}$ and a dialysis membrane. ${ }^{19}$ Although the speciation data obtained by these methods are useful to evaluate the toxicity and/or bioavailability of copper, little information from the data can be obtained for other metal ions that are biologically and geochemically important. ${ }^{20}$

Midorikawa et al. ${ }^{20}$ reported a newly developed method to measure the complexing ability of organic ligands in seawater for copper(II) and cadmium(II): natural ligands in seawater are concentrated and desalted by lyophilization and dialysis, the concentrated solution is electrodialyzed with ethylenediaminetetraacetic acid to remove metal ions using a dialysis membrane, and the demetalized ligands obtained are titrated with copper(II) and cadmium(II) solutions to determine the complexing ability using the corresponding ion-selective electrodes. Chromium(III) binding abilities of humic acid were evaluated by using a cation-exchanger, sulfopropyl Sephadex C-25, in which the cationic unbound chromium(III) species are retained on the resin. ${ }^{21}$ Bidoglio et al. ${ }^{22}$ reported on the complexation of europium(III) and terbium(III) with fulvic acids as well as the competition between aluminum(III) and

$\doteqdot$ To whom correspondence should be addressed.

N. T. present address: Department of Applied Chemistry, Aichi Institute of Technology, Toyota 470-0392, Japan.
europium(III) in a fulvic acid system using timeresolved laser-induced fluorescence. Hawke et al. ${ }^{23}$ reported an FIA method for the estimation of AlCC of fulvic acids in soil and natural water with photometric detection using Chrome Azurol S: the analytical signal from this method arises from both free aluminum(III) and aluminum(III) bound in labile complexes, but not aluminum(III) bound in non-labile complexes with natural ligands. As described above, few reports concerning various metal $\mathrm{CC}$ values obtained by the same method have appeared. Such reports would provide speciation data of individual metals and much information about water analysis.

Recently, we have proposed a reverse FIA (r-FIA) photometric method for the determination of trace amounts of complexing agents such as EDTA, NTA, citrate and diphosphate. ${ }^{24}$ It is based on the accelerating effect of such complexing agents on the rate of the redox reaction of copper(II) with iron(II) in the presence of neocuproine. In this redox system, a copper(I)neocuproine complex with an absorption maximum at $454 \mathrm{~nm}$ is produced. In addition, we showed that the accelerating effect of these complexing agents on the formation of copper(I)-neocuproine is retarded by adding metal ions such as $\mathrm{Al}(\mathrm{III}), \mathrm{Cu}(\mathrm{II}), \mathrm{Zn}$ (II), $\mathrm{Cd}(\mathrm{II})$ and $\mathrm{Pb}(\mathrm{II})$ : a decrease in the absorbance at $454 \mathrm{~nm}$ is observed. By this phenomenon, a measurement of some metal ion CC of EDTA and/or diphosphate. ${ }^{24}$ In the present work, several conditions of the method for the measurement of $\mathrm{Al}(\mathrm{III}), \mathrm{Zn}(\mathrm{II}), \mathrm{Cd}(\mathrm{II}), \mathrm{In}(\mathrm{III})$ and $\mathrm{Pb}$ (II) $\mathrm{CC}$ are presented in more detail; especially the InCC is of interest because it is equally obtained for both EDTA-(aminopolycarboxylic acid) and diphosphate-type ligands. The proposed method was evaluated by measuring the $\mathrm{CC}$ values of a mixed solution of EDTA and diphosphate.

\section{Experimental}

\section{Reagents}

All reagents were of analytical-reagent grade and 


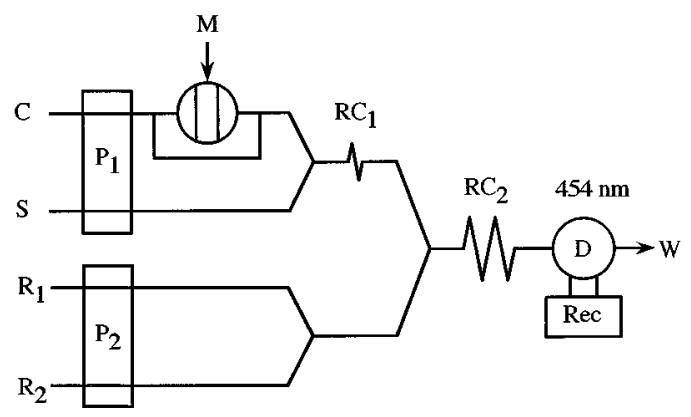

Fig. 1 Flow diagram of FIA for measuring the complexing capacity. C, acetate buffer solution; S, EDTA and/or diphosphate solution; $\mathrm{R}_{1}$, iron(II) solution; $\mathrm{R}_{2}$, a mixed solution of copper(II), neocuproine and acetate buffer; $\mathrm{M}$, metal ion solution (Al(III), $\mathrm{Cr}(\mathrm{III}), \mathrm{Ni}(\mathrm{II}), \mathrm{Zn}$ (II), Cd(II), In(III) and $\mathrm{Pb}(\mathrm{II})$ ) involving acetate buffer solution; $\mathrm{P}_{1}$ and $\mathrm{P}_{2}$, pump; $\mathrm{RC}_{1}, 2.5$ $\mathrm{cm}$ long coil; $\mathrm{RC}_{2}, 100 \mathrm{~cm}$ long coil; $\mathrm{D}$, spectrophotometer (454 nm); Rec, recorder; W, waste.

used without further purification. The water used to prepare the solutions was obtained from a Milli-Q water purification system (Millipore, Tokyo, Japan).

Stock solutions of iron(II) $\left(1 \times 10^{-2} \mathrm{M}\right)$, copper(II) $\left(1 \times 10^{-2} \mathrm{M}\right)$ and neocuproine $(0.1 \mathrm{M})$ were prepared as described previously. 25

Solutions of metal ions injected into FIA system were prepared as follows. Aluminum(III) $(0.1 \mathrm{M})$, zinc(II) $(0.1 \mathrm{M})$ and cadmium(II) solutions were the same as described previously. ${ }^{24,26}$ A chromium(III) solution (0.1 M) was prepared by dissolving $4.00 \mathrm{~g}$ of chromium(III) nitrate nonahydrate in $100 \mathrm{ml}$ of water. A lead(II) solution $(0.1 \mathrm{M})$ was prepared by dissolving $3.31 \mathrm{~g}$ of lead nitrate in $100 \mathrm{ml}$ of water. Nickel(II) and indium(III) solutions were prepared by diluting stock standard solutions for atomic absorption spectrophotometry with water, respectively. Working solutions of these metal ions were prepared by suitable dilution with a $5 \times 10^{-2} \mathrm{M}$ of acetate buffer solution ( $\mathrm{pH}$ ).

Complexing agent solutions of EDTA and diphosphate $(0.1 \mathrm{M})$ were prepared as described previously. ${ }^{26}$

\section{Apparatus}

Figure 1 shows a schematic r-FIA diagram for the measurement of CC. Two double-plunger micro pumps (Sanuki Kogyo, DMX-2000) and a six-way injection valve (Sanuki Kogyo, SVM-6M2) were used to assemble the system. The flow lines were made from PTFE (polytetrafluoroethylene) tubing (1 mm i.d.). The absorbance change was monitored at $454 \mathrm{~nm}$ with a spectrophotometer (Soma Kogaku, S-3250) equipped with a $10-\mathrm{mm}$ micro flow cell $(8 \mu \mathrm{l})$ and recorded on a recorder (Chino, EB 22005). The $\mathrm{pH}$ of the waste solution was continuously monitored with a $\mathrm{pH} / \mathrm{mV}$ meter (Corning, Model 12).

\section{Procedure}

In the flow system as shown in Fig. 1 , a $5 \times 10^{-2} \mathrm{M}$ of acetate buffer solution ( $\mathrm{pH} 5)$ as a carrier solution in reservoir C, EDTA and/or diphosphate solution in reservoir $\mathrm{S}$, a $1 \times 10^{-4} \mathrm{M}$ of iron(II) solution in reservoir $\mathrm{R}_{1}$ and a mixed solution of copper(II) $\left(1 \times 10^{-4} \mathrm{M}\right)$, neocuproine $\left(5 \times 10^{-4} \mathrm{M}\right)$ and acetate buffer $\left(5 \times 10^{-2} \mathrm{M}\right.$, $\mathrm{pH} 5$ ) in reservoir $\mathrm{R}_{2}$ were pumped at a flow rate of 2.6

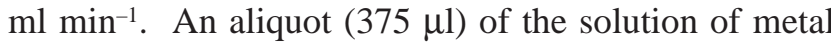
ions $\left(2 \times 10^{-5} \mathrm{M}\right)$ such as $\mathrm{Al}(\mathrm{III}), \mathrm{Cr}(\mathrm{III}), \mathrm{Ni}(\mathrm{II}), \mathrm{Zn}(\mathrm{II})$, $\mathrm{Cd}(\mathrm{II}), \mathrm{In}(\mathrm{III})$ and $\mathrm{Pb}(\mathrm{II})(\mathrm{M})$ was injected by the injection valve into the carrier stream $(\mathrm{C})$. A decrease in absorbance at $454 \mathrm{~nm}$ was recorded.

\section{Results and Discussion}

A redox reaction of iron(II) with copper(II) in the presence of neocuproine proceeds quantitatively, producing a copper(I)-neocuproine complex with an absorption maximum at $454 \mathrm{~nm}$. This redox reaction is extremely accelerated in the presence of complexing agents such as EDTA and/or diphosphate. ${ }^{27}$ However, the accelerating effect of these two complexing agents on the redox reaction is retarded by adding metal ions such as $\mathrm{Al}(\mathrm{III}), \mathrm{Zn}(\mathrm{II}), \mathrm{Cd}(\mathrm{II}), \mathrm{Pb}(\mathrm{II})$ and $\mathrm{In}(\mathrm{III})$. In the flow system as shown in Fig. 1, EDTA and diphosphate solutions were pumped as a model ligand in natural water. In the absence of metal ions for the $\mathrm{CC}$ measurement, the redox reaction is accelerated in the presence of EDTA or diphosphate. A constant absorbance of the copper(I)-neocuproine complex was obtained. Then, each metal ion was injected into an acetate buffer solution. The metal ion injected reacted with EDTA and/or diphosphate to form a corresponding complex in a reaction coil $\mathrm{RC}_{1}$, so that a negative FIA peak was obtained. The peak height corresponded to the concentration of each ligand. Thus, the $\mathrm{CC}$ values for various metal ions can be determined by measuring the decrease in absorbance at $454 \mathrm{~nm}$.

Various metal ions complexing capacity corresponding to EDTA and diphosphate as model ligands

The $\mathrm{CC}$ values of metal ions such as $\mathrm{Al}(\mathrm{III}), \mathrm{Cr}(\mathrm{III})$, $\mathrm{Ni}(\mathrm{II}), \mathrm{Zn}(\mathrm{II}), \mathrm{Cd}(\mathrm{II}), \mathrm{In}(\mathrm{III})$ and $\mathrm{Pb}(\mathrm{II})$ were measured under the following conditions: $C_{\mathrm{EDTA}}$ or diphosphate $=1 \times 10^{-5}$ $\mathrm{M}, \mathrm{RC}_{1}=2.5 \mathrm{~cm}, \mathrm{RC}_{2}=65 \mathrm{~cm}$ and $V_{\text {metal ion injected }}=140 \mu \mathrm{l}$. In the case of EDTA, the maximum and almost constant values for $\mathrm{ZnCC}, \mathrm{CdCC}$, InCC and $\mathrm{PbCC}$ were obtained. The AlCC and NiCC values were very low, and the $\mathrm{CrCC}$ value was not obtained because the rates of complex formation of $\mathrm{Al}(\mathrm{III}), \mathrm{Ni}$ (II) and $\mathrm{Cr}(\mathrm{III})$ were slower than those of other metal ions. In the case of diphosphate, the AlCC and InCC were obtained, while other CC values were not obtainable.

The effects of the EDTA and diphosphate concentrations were examined over the range $2 \times 10^{-6}-1 \times 10^{-5} \mathrm{M}$. In the case of EDTA, the InCC, $\mathrm{ZnCC}, \mathrm{CdCC}$ and $\mathrm{PbCC}$ values were the same and linearly increased with increasing EDTA concentration, while the AlCC values were very low. In the case of diphosphate, the AlCC and InCC values linearly increased with increasing 

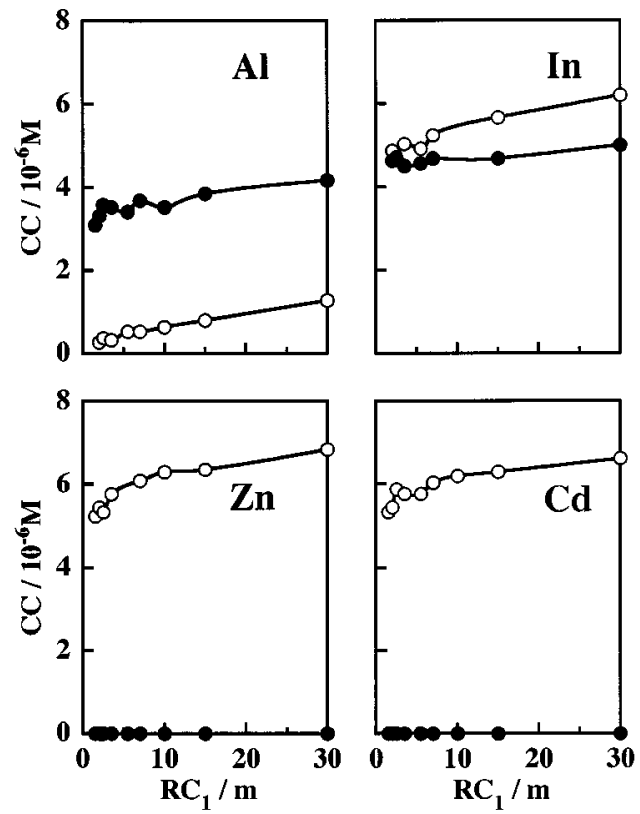

Fig. 2 Effect of the reaction coil length of $\mathrm{RC}_{1}$ on the $\mathrm{CC}$ values. Complexing agents $\left(2 \times 10^{-5} \mathrm{M}\right)$ : $(0)$, EDTA; $(\bullet)$, diphosphate. Other conditions as in the text.

diphosphate concentration, while the $\mathrm{ZnCC}, \mathrm{CdCC}$ and $\mathrm{PbCC}$ values were not obtainable. From the above results, a characterization of complexing agents in natural water samples should be possible by the proposed method; the AlCC values represent diphosphate type ligands, and the $\mathrm{ZnCC}, \mathrm{CdCC}$ and $\mathrm{PbCC}$ values correspond to aminopolycarboxylic acid type ligands. As described later, it is emphasized that the InCC values correspond to two types of ligands.

\section{Effect of the experimental variables}

The experimental conditions such as the reaction $\mathrm{pH}$, injection volume of metal ion and lengths of $\mathrm{RC}_{1}$ and $\mathrm{RC}_{2}$ were examined by injecting a $2 \times 10^{-5} \mathrm{M}$ solution of each metal ion of $\mathrm{Al}(\mathrm{III}), \mathrm{Zn}(\mathrm{II}), \mathrm{In}(\mathrm{III})$ and $\mathrm{Cd}(\mathrm{II})$. A $1 \times 10^{-5} \mathrm{M}$ of EDTA or diphosphate solution was pumped from reservoir $\mathrm{S}$.

The effect of the $\mathrm{pH}$ of the solution on the $\mathrm{CC}$ values was examined over the range $4.7-5.6$. In the case of EDTA, the maximum and almost constant values were obtained for InCC, $\mathrm{ZnCC}$ and $\mathrm{CdCC}$ at $\mathrm{pH} 4.7$ - 5.6. In the case of diphosphate, the AlCC and InCC values rapidly increased with increasing $\mathrm{pH}$ of the solution. For the procedure, a $\mathrm{pH}$ around 5 was used because the AlCC value with EDTA was relatively low at this $\mathrm{pH}$.

The effect of volume of metal ion solution injected was examined over the range $140-535 \mu \mathrm{l}$. In the case of EDTA, the InCC, $\mathrm{ZnCC}$ and $\mathrm{CdCC}$ values gradually increased with increasing the injection volume of metal ion solutions, and the AlCC values were very low. In the case of diphosphate, the AlCC and InCC values were obtainable and increased with increasing the injection volume. A $375 \mu \mathrm{l}$ of injection volume was selected for the procedure.
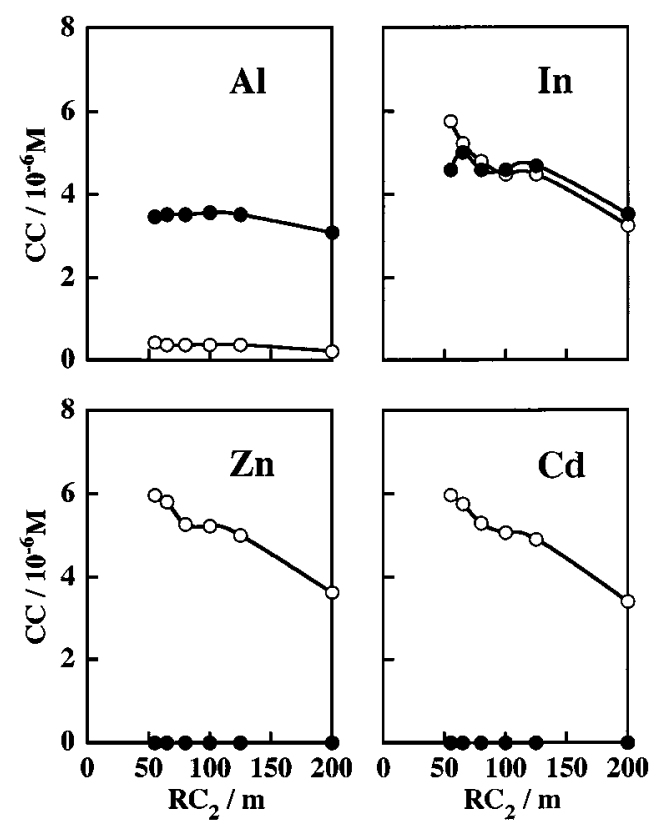

Fig. 3 Effect of the reaction coil length of $\mathrm{RC}_{2}$ on the $\mathrm{CC}$ values. Complexing agents $\left(2 \times 10^{-5} \mathrm{M}\right)$ : (o), EDTA; (•), diphosphate. Other conditions as in the text.

The effect of the reaction coil length of $\mathrm{RC}_{1}$ was examined over the range $1.5-30 \mathrm{~cm}$. The results are shown in Fig. 2. In $\mathrm{RC}_{1}$, injected metal ions reacted with complexing agents to form corresponding complexes. In the case of diphosphate, the $\mathrm{ZnCC}$ and CdCC values were not obtained, and the AlCC and InCC values gradually increased with increasing the $\mathrm{RC}_{1}$ length. In the case of EDTA each $\mathrm{CC}$ value increased with increasing the $\mathrm{RC}_{1}$ length, probably because the time of complex formation of each metal ion with EDTA became longer with increasing the $\mathrm{RC}_{1}$ length. Taking into account the lower value for AlCC, a $2.5 \mathrm{~cm}$ long of $\mathrm{RC}_{1}$ was used for the procedure.

Figure 3 shows the effect of the $\mathrm{RC}_{2}$ length. The InCC values were almost the same in the cases of both EDTA and diphosphate compared with other metal ions. A $100 \mathrm{~cm}$ long of $\mathrm{RC}_{2}$ was used for the procedure.

\section{Complexing capacity of synthetic mixtures of EDTA and diphosphate}

Under the established conditions, the AlCC, InCC, ZnCC and CdCC of synthetic mixtures of EDTA and diphosphate were measured. As shown in Fig. 4, the $\mathrm{ZnCC}$ and CdCC values increased with increasing EDTA contents, whereas the AlCC values increased with increasing the diphosphate contents. The InCC values were equally obtained for EDTA and diphosphate type ligand. From these flow signals, EDTA and diphosphate contents were estimated. The results are summarized in Table 1. The contents of EDTA were calculated from the ratio of $\mathrm{ZnCC} / \mathrm{InCC}$, and those of diphosphate were calculated from AlCC/InCC. The recovery of diphosphate was found to be satisfactory. 
(a)

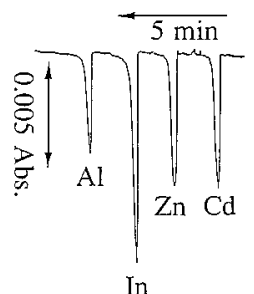

(b)

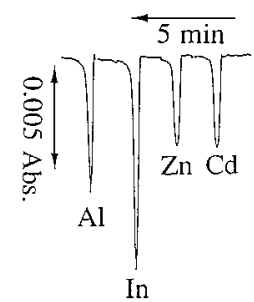

(c)

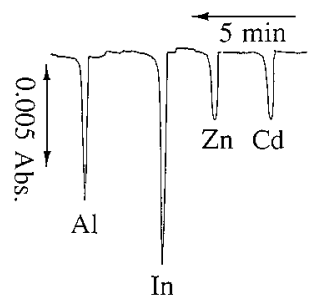

Fig. 4 Flow signals for the $\mathrm{CC}$ of mixed solutions of EDTA and diphosphate $\left([\right.$ EDTA $]+[$ diphosphate $\left.]=1 \times 10^{-5} \mathrm{M}\right)$ for $\mathrm{Al}(\mathrm{III}), \mathrm{In}(\mathrm{III}), \mathrm{Zn}(\mathrm{II})$ and $\mathrm{Cd}(\mathrm{II})$. EDTA(\%)/diphosphate (\%): (a), 50/50; (b), 33/67; (c), 25/75.

The values of EDTA found decreased with decreasing EDTA contents. Although the proposed method was not evaluated in full detail, it is useful for estimating two types of CC in natural water samples.

\section{References}

1. C. M. G. van den Berg, Anal. Chim. Acta, 284, 461 (1994).

2. K. Yokoi, Bunseki, 1996, 108.

3. M. Gledhill, M. Nimmo, S. J. Hill and M. T. Brown, $J$. Phycol., 33, 2 (1997).

4. R. Kunkel and S.E. Manahan, Anal. Chem., 45, 1465 (1973).

5. M. S. Shuman and G. P. Woodward, Anal. Chem., 45, 2032 (1973).

6. E. W. Davey, M. J. Morgan and S. J. Erickson, Limnol. Oceanogr., 18, 993 (1973).

7. B. T. Hart, Envir. Technol. Lett., 2, 95 (1981).

8. T. M. Florence, Talanta, 29, 345 (1982).

9. T. A. Neubecker and H. E. Allen, Water Res., 17, 1 (1983).

10. V. N. Iyer and R. Sarin, Anal. Lett., 25, 1915 (1992).

11. G. Scarano, E. Bramanti and A. Zirino, Anal. Chim. Acta, 264, 153 (1992).

12. M. L. A. M. Campos and C. M. G. van den Berg, Anal. Chim. Acta, 284, 481 (1994).

13. K. Isshiki, Bunseki Kagaku, 43, 851 (1994).

14. L. J. Spokes, M. L. A. M. Campos and T. D. Jickells,
Table 1 Estimation of EDTA and diphosphate contents (\%) from the $\mathrm{CC}$ values

\begin{tabular}{ccccc}
\hline \multicolumn{2}{c}{ Synthetic mixture $^{\mathrm{a}}$} & & \multicolumn{2}{c}{ Found } \\
\cline { 1 - 2 } \cline { 5 - 5 } EDTA & Diphosphate & & EDTA & Diphosphate \\
\hline 75 & 25 & & 91 & 25 \\
67 & 33 & & 85 & 33 \\
50 & 50 & & 64 & 49 \\
33 & 67 & & 44 & 64 \\
25 & 75 & & 33 & 69 \\
\hline
\end{tabular}

a. $[$ EDTA $]+[$ diphosphate $]=1 \times 10^{-5} \mathrm{M}$.

Atmos. Environ., 30, 3959 (1996).

15. H. Kawamoto, W. Ishida, K. Tsunoda and H. Akaiwa, Bull. Chem. Soc. Jpn., 65, 3485 (1992).

16. Y. Sasaki, S. Koizumi, T. Yoshikuni and A. Yamada, Bunseki Kagaku, 43, 1053 (1994).

17. H. Itabashi, H. Kawamoto, N. Niibe, K. Tsunoda and H. Akaiwa, Anal. Sci., 11, 263 (1995).

18. M. Taga, S. Tanaka and M. Fukushima, Anal. Sci., 6, 611 (1990).

19. T. Midorikawa and E. Tanoue, Anal. Chim. Acta, 284, 605 (1994).

20. T. Midorikawa, E. Tanoue and Y. Sugimura, Anal. Chem., 62, 1737 (1990).

21. M. Fukushima, K. Nakayasu, S. Tanaka and H. Nakamura, Anal. Chim. Acta, 317, 195 (1995).

22. G. Bidoglio, I. Grenthe, P. Qi, P. Robouch and N. Omenetto, Talanta, 38, 999 (1991).

23. D. J. Hawke, K. J. Powell and J. E. Gregor, Mar. Freshwater Res., 47, 11 (1996).

24. N. Teshima, H. Itabashi and T. Kawashima, Talanta, 40, 101 (1993).

25. H. Itabashi, K. Umetsu, K. Satoh and T. Kawashima, Anal. Sci., 6, 721 (1990).

26. K. Umetsu, H. Itabashi, K. Satoh and T. Kawashima, Anal. Sci., 7, 115 (1991).

27. H. Itabashi, K. Umetsu, N. Teshima, K. Satoh and T. Kawashima, Anal. Chim. Acta, 261, 213 (1992).

(Received March 15, 1999) (Accepted May 15, 1999) 